\title{
The risks for thromboembolism following caesarean section
}

\author{
Veena R. ${ }^{1}$, Radhamani M. V. ${ }^{*}$, Deepa $S .{ }^{2}$ \\ ${ }^{1}$ Department of Obstetrics and Gynecology, ${ }^{2}$ Department of Radiodiagnosis, Government Medical College, Kottayam, \\ Kerala, India
}

Received: 08 December 2018

Accepted: 15 January 2019

\section{*Correspondence:}

Dr. Radhamani M. V.,

E-mail: drmvradhamani@ gmail.com

Copyright: (c) the author(s), publisher and licensee Medip Academy. This is an open-access article distributed under the terms of the Creative Commons Attribution Non-Commercial License, which permits unrestricted non-commercial use, distribution, and reproduction in any medium, provided the original work is properly cited.

\section{ABSTRACT}

Background: Maternal mortality can be due to various reasons. Maternal mortality following thromboembolism is a cause for concern. Venous thromboembolism is a very serious condition following caesarean section. Thromboprophylaxis should be given to the mothers with high risk for thromboembolism, who deliver by caesarean section. The objective of this study was to do to assess the risk status for thromboembolism among women delivered by caesarean section.

Methods: A hospital based cross- sectional study was conducted among four hundred mothers who delivered by caesarean section. The study was conducted for a period of eight months from January to August 2017. The risks for thromboembolism was assessed and as per the guideline and hospital policy, thromboprophylaxis was given.

Results: Out of four hundred patients, medical comorbidities were present for three patients. Patients who were overweight were 122. Two had systemic infection. The number of patients with high, intermediate and low risk of venous thromboembolism were 4,65 and 331 .

Conclusions: The study suggests that thromboprophylaxis is to be given for all the patients with any risk for thromboembolism, after caesarean section.

Keywords: High risk, Intermediate risk, Thromboembolism, Thromboprophylaxis

\section{INTRODUCTION}

Maternal mortality and morbidity following child birth has reduced worldwide. But the maternal mortality is still a reason for concern. There are several causes that contribute to maternal deaths. Of that, venous thromboembolism (VTE) is an important and preventable cause but the condition should be managed timely. ${ }^{1}$ It is known that pregnancy is a hypercoagulable state and venous stasis occurs. Women are at risks of VTE during pregnancy and puerperium.

Both physiological factors and other factors may lead to VTE. Caesarean section itself is a risk factor. Others include obesity, high parity, infection, pre-eclampsia, dehydration and immobility. Family history also has a role. The incidence of deep vein thrombosis (DVT) is $1.72 / 1000$ deliveries and 1.1 deaths per one lakh. ${ }^{2}$

Various studies showed that thromboprophylaxis definitely has a role but in the current set up, Indian guidelines for the prevention of thromboembolism is not there.

Efficacy and safety of low molecular weight heparin (LMWH) have been studied by authors and has been shown as very effective in preventing venous thromboembolism. ${ }^{3-5}$

According to another study, unfractionated heparin can be safely used for thromboprophylaxis in post-partum period. ${ }^{6}$ 
Another study stated LMWH was safe and effective.? Another study suggested that vigilance should be there in implementing thromboprophylaxis. ${ }^{8}$ It has already been shown that the patient's compliance is also very important in thromboprophylaxis. ${ }^{9}$ Another assessment from Kerala, showed that $26 \%$ of total maternal deaths were due to thromboembolism. These showed that caesarean section increases the chance of venous thromboembolism nine-fold as compared to vaginal delivery. ${ }^{10}$ Women are at increased risk of thromboembolism during pregnancy about four- fivefold risk, compared to non-pregnant state. ${ }^{11}$ The incidence of venous thromboembolism is less than $1 \% .^{12,13}$

There are several risk factors for thromboembolism in pregnancy. These include multiple pregnancy, obesity, smoking, sedentary life style, immobilisation, previous history of VTE, assisted reproduction technology, gestational diabetes, age older than 35 years, primiparity, preeclampsia, abruption placenta and placenta previa. ${ }^{14-18}$ Obesity is a well-studied risk factor for occurrence of thromboembolism in pregnancy. . 16,17

Hence this study was done to find out the risks for thromboembolism among women admitted and delivered by caesarean section.

\section{METHODS}

A descriptive study was conducted among 400 women who has undergone caesarean section from January to August 2017 for a period of eight months, in Government Medical college, Kottayam. This study was done to assess the proportion of patients who are at risk, of various grades and thus needed thromboprophylaxis following caesarean section.

\section{Inclusion criteria}

- All the women who underwent caesarean section were included for the study.

\section{Exclusion criteria}

- Patients with seriously morbid conditions and bed ridden patients were excluded from the study. By consecutive sampling, all the eligible patients were included until the required sample was obtained.

They were personally interviewed using a pre-tested and structured questionnaire. Informed written consent was taken in their local language from each subject. There are no risks involved in the study. Confidentiality of the subjects is also preserved.

\section{Statistical analysis}

The data obtained was coded and entered in Microsoft excel sheet and analysed using statistical package for social sciences (SSPS version-23).

\section{RESULTS}

The study was conducted among 400 women who had undergone caesarean section.

Majority of the women were in 21-30-year age group, which is $214(53.5 \%)$, followed by $198(49.5 \%)$ belonged to parity $1-3$. The women who had undergone caesarean section in labour (emergency CS) were 173 (43.25\%), which itself is an intermediate risk factor group.

The indications were arrest of descent, arrest of dilatation, persistent variable deceleration and meconium stained amniotic fluid.

Table 1: Variables related to the mother.

\begin{tabular}{|l|l|l|l|}
\hline \multicolumn{2}{|c|}{ Variables } & Frequency & Percentage \\
\hline Medical comorbidities & 3 & 0.75 \\
\hline \multirow{2}{*}{$\begin{array}{l}\text { Body } \\
\text { weight }\end{array}$} & $\begin{array}{l}\text { Overmal } \\
\text { weight }\end{array}$ & 247 & 61.75 \\
\cline { 2 - 4 } & Obesity & 31 & 30.5 \\
\hline $\begin{array}{l}\text { Current } \\
\text { systemic } \\
\text { infection }\end{array}$ & Yes & 8 & 7.75 \\
\hline
\end{tabular}

As shown in Table1, medical comorbidities were there for three subjects $(0.75 \%)$. Body weight was normal for $247(61.75 \%)$ subjects.

The subjects who were overweight were 122(30.5\%) and obese were $31(7.75 \%)$. Eight $(2 \%)$ had current systemic infection.

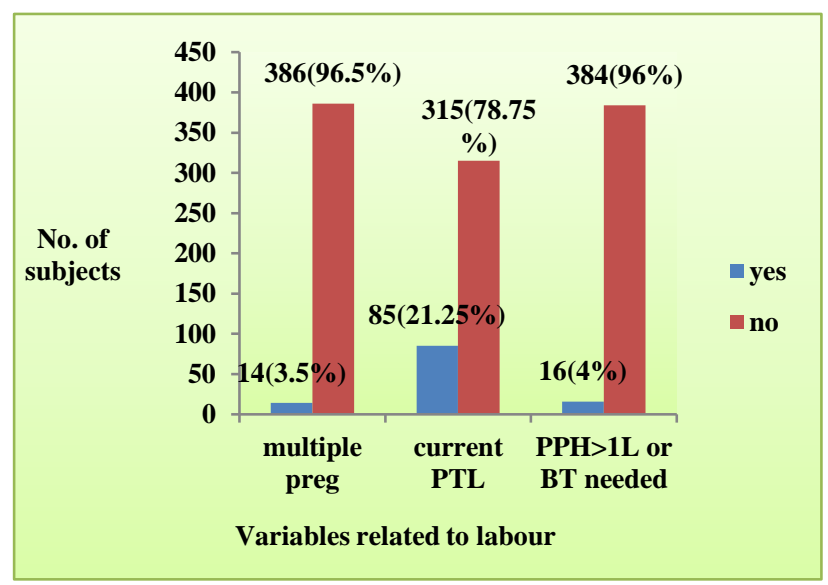

Figure 1: Distribution of subjects based on variables related to labour.

As shown in Figure 1, fourteen of the study subjects had multiple pregnancy.

Eighty-five $(21.25 \%)$ subjects had preterm labour for the current pregnancy. Sixteen $(4 \%)$ of them had PPH or blood transfusion required for the current pregnancy. 
Table 2: Grades of risk for thrombosis.

\begin{tabular}{|l|l|l|l|}
\hline Risk & $\begin{array}{l}\text { Previous } \\
\text { HTEh }\end{array}$ & 1 & 0.25 \\
\hline VTE & $\begin{array}{l}\text { Required } \\
\text { antenatal } \\
\text { LMWH }\end{array}$ & 3 & 0.75 \\
\hline Intermediate & $\begin{array}{l}\text { According } \\
\text { to hospital } \\
\text { policy } \\
\text { According } \\
\text { Low }\end{array}$ & 65 & 16.25 \\
\hline $\begin{array}{l}\text { to hospital } \\
\text { policy }\end{array}$ & 331 & 82.75 \\
\hline
\end{tabular}

The number of women who are candidates for thromboprophylaxis as per hospital policy was 69 (16.25\%). These include four high risk and 65 intermediate risk group.

\section{DISCUSSION}

Maternal mortality and morbidity can be prevented to a great extent if thromboprophylaxis is provided to the required patients. Caesarean section itself is considered as a risk for thromboembolism in pregnancy. Thromboprophylaxis is an effective method to prevent life threatening thromboembolic episode. Pulmonary embolism has got a very high mortality rate. In this study, the risks of thromboembolism were categorized into grades of high, intermediate and low risk. Study from Kerala showed that caesarean section increases the chance of venous thromboembolism nine-fold as compared to normal vaginal delivery. ${ }^{10}$ In this study, none of the study population developed features of VTE. Efficacy and safety of LMWH have been studied by authors in UK, Italy and Ireland..$^{3,4,5}$ According to a study, unfractionated heparin can be safely used for thromboprophylaxis in post-partum period. ${ }^{6}$ According to Blondon et.al., LMWH was safe and effective. ${ }^{7}$ Another study suggested that greater vigilance should be there in implementing thromboprophylaxis. ${ }^{8}$ Multiple pregnancy and obesity are known risk factors for VTE. ${ }^{14,16}$ Fourteen $(3.5 \%)$ had multiple pregnancy in the present study, while $38 \%$ were overweight and obese. The incidence of postpartum hemorrhage can be up to $70 \%$ in morbidly obese women. ${ }^{19,20}$ Thromboembolic disease is also more frequent in obese women. ${ }^{21,22}$ It is there for both emergency and elective caesarean section but higher with emergency CS. ${ }^{23}$ Hypertension and the presence of varicose veins were associated with $\mathrm{TE}$ following $\mathrm{CS}^{24}$ Increased BMI (OR 3.42; 95\% CI 2.87-4.06), emergency CS (OR 1.88; 95\% CI 1.67-2.16) and older maternal age (OR 1.37; 95\% CI 1.26-1.49) were associated with more frequent LMWH use. ${ }^{25}$

\section{CONCLUSION}

This study suggests that there are risks involved in caesarean section for thromboembolism. As part of
RCOG guidelines and hospital policy, the patients who were needed thromboprophylaxis have been given the same. And none of them developed VTE, this finding is very important even though this was not the objective of my study. Thus, this study also suggests that thromboprophylaxis is satisfactory and effective in preventing thromboembolism. There needs a multicentric study for assessing the risks of developing VTE among post LSCS patients and to establish an Indian guideline for thromboprophylaxis.

\section{Funding: No funding sources}

Conflict of interest: None declared

Ethical approval: The study was approved by the Institutional Ethics Committee

\section{REFERENCES}

1. Nelson-Piercy C, MacCallum P, Mackillop L. Reducing the risk of thrombosis and embolism during pregnancy and puerperium. Royal College of Obstetricians and Gynaecologists, green-top Guidelines. No 37a April 2015; Available at: http://www.rcog.org.uk/files/rcogcorp/GTG37aRedu cingRiskThrombosis.pdf.

2. James AH. Prevention and management of venous thromboembolism in pregnancy. Am $\mathrm{J}$ Med. 2007;12(10):S26-34.

3. Gidiri M, Sant M, Philips $K$, Lindow SW. Thromboprophylaxis for caesarean section- how can uptake and coverage be improved?. J Obstet Gynaecol. 2004;24(4):392-4.

4. Cavazza S, Rainaldi MP, Adduci A, Palareti G. Thromboprophylaxis following caesarean delivery: One site prospective pilot study to evaluate the application of a risk score model. Thrombosis Res. 2012;129(1):28-31.

5. Crowley MP, Noone C, Higgins JR, O' Shea S. A multicentre study of thromboprophylaxis in Pregnancy. Ir Med J. 2017;110(5):567.

6. Shakuntala PN, Jhancy AD, Rabia M, Shalini N, SK S, PadminiIsacc SR. Risk Scoring and Appraisal of Thromboprophylaxis following emergency caesarean section- A pilot study. Int J Health Scienc Res. 2013;3(8):22-30.

7. Blondon M. Thromboprophylaxis after caesarean section: decision analysis. ThrombRes.2011;127(3): S9-12.

8. Tomialowicz M, Florjanski J, Zimmer M, Pajak J, Klosek A. Assessment of the effectiveness of using low molecular weight heparin in the prophylaxis of venous thrombo-embolic diseases in obstetrics. Ginekol Pol. 2000;71(9):1115-9.

9. Lau CQH, Wong TCT, Tan EL, Kanagalingam D. A review of caesarean section techniques and postoperative thromboprophylaxis at a tertiary hospital. Singapore Med J. 2017;58(6):327-31.

10. Paily VP, Anbujam K, Rajasekharan Nair V, Thomas B. Confidential review of maternal deaths in 
Kerala: a country case study. BJOG: Int J Obstetrics Gynaecol. 2014;121(s4):61-6.

11. James AH. Pregnancy-associated thrombosis. Hematol.2009;2009(1):277-85

12. Jacobsen A, Drolsum A, Einar Klow N, Dahl G, Qvigstad E, Sandset PM. Deep vein thrombosis after elective caesarean section. Thrombosis Res. 2004;113:283-8.

13. Rudigoz RC, Arnaud MF, Dargent D, Magnin P. The risk of thrombo-embolism in pregnancy and in the post-partum period. A review of 28,828 pregnancies author's transll. J Gynecol Obstet Biol Reprod. 1981;10(2):155-61.

14. Jacobsen AF, Skjeldestad FE, Sandset PM. Anteand post-natal factors of venous thrombosis: a hospital-based case-control study. J Thromb Haemost.2008;6(6):905-12

15. Jacobsen AF, Skjeldestad FE, Sandset PM. Incidence and risk patterns of venous thromboembolism in pregnancy and puerperium- a register-based casecontrol study. Am J Obstetr gynecol. 2008;198(2):233-e1.

16. Malinowski AK. Bomba-Opon D, Parrish J, Sarzynska U, farine D. Venous thromboembolism in obese pregnant women: approach to diagnosis and management. Ginekol Pol. 2017;88(8):453-9.

17. Robinson HE, O'Connell CM, Joseph KS, McLeod NL. Maternal outcomes in pregnancies complicated by obesity. Obstet Gynecol. 2005;106(6):1357-64.

18. Danilenko-Dixon DR, Heit JA, Silverstein MD, Yawn BP, Petterson TM, Lohse CM, et al. Risk factors for deep vein thrombosis and pulmonary embolism during pregnancy or post-partum: A population-based case control study. Am J Obstet Gynecol. 2001;184(2):104-10.
19. Baeten JM, Bukusi EA, Lambe M. Pregnancy complications and outcomes among overweight and obese nulliparous women. Am J Public Health. 2001;91:436-40.

20. Sebire NJ, Jolly M, Harris JP, Wadsworth J, Joffe M, Beard RW, et al. Maternal obesity and pregnancy outcome: A study of 287,213 pergnancies in London. Int J Obes Relat Metab Disord. 2001;25:1175-82.

21. Perlow JH, Morgan MA. Massive maternal obesity and perioperative cesarean morbidity. Am J Obstet Gynecol. 1994;170:560-5.

22. Edwards LE, Hellerstedt WL, Alton IR, Story M, Himes JH. Pregnancy complications and birth outcome in obese and normal weight women: effects of gestational weight change. Obstet Gynecol. 1996;87:389-94.

23. Blondon M, Casini A, Hoppe KK, Boehlen F, Righini M, Smith NL.Risks of Venous Thromboembolism After Cesarean Sections: A Meta-Analysis. Chest Journal.2016;150:572-96.

24. Joyce Lai, Isvarya Venu, Ann Kinga Malinowski, Shital Gandhi, Anne McLeod, Rosane Nisenbaum, et al. Thromboembolism following cesarean section: a retrospective study, Hematol.2018;23:6, 351-6.

25. Seeho SK, Nippita TA, Roberts CL, Morris JM, Nassar N. Venous thromboembolism prophylaxis during and following caesarean section: a survey of clinical practice. Aus New Zeal J Obstetr Gynaecol. 2016;56(1):54-9.

Cite this article as: Veena $\mathrm{R}$, Radhamani MV, Deepa S. The risks for thromboembolism following caesarean section. Int J Reprod Contracept Obstet Gynecol 2019;8:1167-70. 